\title{
Water-Born Micro-Cities: Bringing the Great Lakes Closer to Natural Symbiosis with Eco-Based Design
}

\author{
Dustin Altschul, Kim Buchholz
}

\begin{abstract}
Through design-based research, we investigate how a water-borne micro-city can participate in ecological repair that also supports healthy, human life by removing harmful algae from the water and utilizing it as a supply resource for energy. In this proposed scenario, urbanism becomes the active component in prevention of toxic algae blooms. By bringing together scientific research with research from medicine, design, history and social science, we begin to animate design strategies that promote local and regional resiliency within the Great Lakes. These hypothetical designs, while focusing on algae within the Great Lakes, can provide a feasible prototype for other coastal regions around the world. The priorities of this project are relatable to all coastal-adjacent settlements and the pending depletion of resources that will jeopardize human life.
\end{abstract}

Keywords: urbanism, built ecologies, Great Lakes, urban design, Freshwater Urbanism

Many coastal settlements are facing vulnerabilities to environmental threats as the discord between the natural environment and human habitation rapidly causes devastating conditions including, but not limited to, flooding, water pollution, shoreline erosion, drought, and toxic living environments. As scientific research unveils data connecting these hazardous environmental indicators to contemporary urbanism, the topic of ecological resilience becomes critically relevant to urban planners and the design community. Marine-based urbanism has revealed an enigma of 
environmental stressors on the oceanic state. However, the subject of the Great Lakes fresh water basins, as well as the network of various lakes and rivers that connect to the larger Great Lakes watershed, in relation to adaptive urban resiliency, has yet to be investigated as a new, speculative urban morphology.

\section{DO NOT DRINK}

Human habitation along the Great Lakes is having a considerable impact on the watersheds that have otherwise had a supply of relatively fresh, unpolluted water prior to the onset of the twentieth century, when industry and large agricultures dominantly developed in the region. Lake Erie, in particular, has continuously suffered a harmful plight while the other Great Lakes have not as severely experienced comparative environmental distress. For the past fifty years, there have been social, political, and environmental efforts made to prevent and alleviate Lake Erie from facing the troubling reality of toxic state, or as the Environmental Protection Agency (EPA) classifies, impaired waters. ${ }^{1}$ Cleanup efforts focus on the infection of the toxic algae itself, rather than confronting the sources of the environmental offending polluters; a recipe of agricultural runoff, storm water runoff, and biological waste, creating an overloading of nutrients into the fresh water, a condition known as "eutrophication." When faced with reports from the EPA regarding the state of impairment of Lake Erie, local city and state officials have tempered the severity of the water condition in fears that the label would cloud Ohio tourism.

The Great Lakes have many filter-feeding organisms that provide a natural cleansing of the fresh water. However, the eutrophication in Lake Erie has repelled these organisms, allowing further proliferation of toxic algae blooms. These hostile algae conditions are directly related to the amount of phosphorous introduced in the water supply. Throughout the Great Lakes, and particularly in Lake Erie, there are numerous supply derivations of contaminants, including various isolated sets of pipelines emptying wastewater into the lakes, as well as runoff from farming and urban infrastructure. Most of the phosphorous pollution, however, is caused by the large amounts of runoff. The over spilling of urban and agricultural environments, such as flooded manure fields and storm sewer backup, discharges into rivers and streams during rainfall, collecting toxins and pollutants from a variety of surfaces before pervading the water basins and larger watershed. In 2011, the Great Lakes saw an increase of rainfall from previous years in the spring, resulting in one of the highest toxic algae outbreaks in history. Only two years later, the Ohio EPA and the City of Toledo issued a "Do Not Drink Advisory" to nearly 500,000 users of the City of Toledo water.

"There are twenty-five public water systems serving a combined population of over 2.6 million that use Lake Erie as their source of water. Ten in the 
Western Basin, thirteen in the Central Basin," the Ohio EPA reported of the dangerous impacts of algae bloom to the Lake Erie Public Water Systems. Yet, per the Follow the Manure Report published by the Environmentally Concerned Citizens of South Central Michigan, a 501(c)(3) organization, 691 gallons [3.141,35 L] of manure from 12 million animals is deposited into human-made, agricultural "lagoons," which directly drain contaminated water into Lake Erie, the same water system responsible for providing fresh drinking water to millions of citizens.

While there have been moves made to prevent heavy rainfall from further carrying contaminated lagoon water to Lake Erie and its connecting tributaries, these efforts only continue to support the very roots of the problem - agriculture practices, urban infrastructural deficiencies - that continually position human habitation against the natural environment. It is necessary to explore the possibilities of discontinuing the propagation of conflict at the origin of the problem, thus investigating human habitation under new terms. Often, the solution to urban resiliency in the Great Lakes region has been one that is more responsive than adaptive or alternative. For example, in the case of toxic algae, scientists and policy makers are seeking out methods to control pollution rather than to stop pollution, creating a major disconnect that impedes the evolution of ecologically-based human habitation while allowing the existing mainstream, socially, and economically accepted ways of life to continue, despite the ongoing and pending environmental damages.

The Follow the Manure Report states that:

"The causes of and solutions to this recurring crisis are being debated by legislators, agency officials, the environmental community, agricultural sector and others, but one thing is certain: dissolved phosphorus from fertilizer and waste entering the water from agricultural facilities - both crop and livestock - plays a significant role in the growth of the toxic algae."

While this discussion is happening, Confined Animal Feeding Operations (CAFO), or factory farms, continue to receive government subsidies to maintain the very operations that cause issues like the Do Not Drink Advisory, in addition to threatening the health of the 2.6 million dependent on Lake Erie for drinking water. In 2016 alone, the federal government provided factory farms in the Western Lake Erie Basin \$41 million in subsidies. It is hard to imagine government officials discussing solutions to clean Lake Erie, while also heavily funding the polluting operations, but this is what is happening. Through current strategic mitigation to reroute runoff from entering the Great Lakes, civilization can continue indulging in harmful practices and lifestyles, curtailing reconsidered notions of how humans could live, including the methods of resilient habitation in coastal areas. 
The current urban architype, one that allows modern civilization to parasitically exist, will cause future civilizations to be in environmental, social, and economic disconnection.

\section{THE URBAN DISCONNECT}

Protecting and preserving social behaviors, as they exist, is a risky intrigue. On one hand, if environmental efforts can mitigate runoff from entering the Great Lakes, then by logic, the lake water will not be contaminated by toxic algae or experience eutrophication. On the other hand, toxic runoff and contamination from biological waste will still be an environmental issue somewhere else, causing new, unforeseen coastal ecological harm. Like the infamous arcade game "Whac-A-Mole," solving an issue by redirecting the problem will only cause another crisis to arise at another point in time. These shortsighted strategies also have the capability to cause unexpected social outcomes, such as displacement, negative health consequences, and environmental injustice towards people impacted unfairly.

The underlying issue, the root of the problem, is not the toxic algae invading Lake Erie. It is the urban disconnection from ecological living. Due to increase in economy, transportation, and global marketplaces, it is possible to have every comfort and survival need met with ease. The emotional and mental relationship between humans and environment has been diminished, as it is no longer necessary to live directly off the land for survival. Imagine a river flowing into a home, a current that brings with it fresh water, and as it flows out from the home, it carries detergents, household chemicals, and biological waste. How would life operate under those circumstances? Without having to mentally consider or visually experience the course of water and its extensive journey into the urban infrastructure through various channels, and then back out into the natural environment, people are relieved from the hardship of knowing or caring. The same thought extends to procuring food in the grocery store, a comfort that does not require people to witness agricultural processes, or more importantly, agricultural waste, transportation of food, packaging processes, or even climate conditions. Every part of the environment that has been involved in a food being harvested, processed, transported, manufactured and packaged is removed from the conventional stream of consciousness.

The existing urban framework surrounding coastal bodies in the Great Lakes region is made up of agriculture, dense urban cities, and urban sprawl. This last element is reminiscent of the traditional new urbanist transect, a lineage from natural land to dense urbanism, zone 1 to zone 6, with continuous suburban zones in-between. The intentional separation of urbanism from the natural environment in the Great Lakes region is further isolated by property management, zoning regulations, building codes, and regional planning. These conglomerate, umbrella policy mandates encourage agriculture and industry to be situated closest to, if 
not within, the countryside and water basins, causing severe environmental damage throughout the Great Lakes region. Ironically, it is these very same political regulators that are currently trying to reroute agricultural runoff from entering Lake Erie; thus, providing short-term resolutions to a long-term problem. The contemporary urban-to-natural system does not foster a sense of responsibility or stewardship to the great majority of the population, including policy-makers themselves. When people relate to the natural environment, there is a deeper understanding of the survival struggles that occur along coastal bodies of water. The very natural resources that allow urban life to exist are slowly being damaged by disconnected urban policy and planning.

The Great Lakes are a popular tourist attraction, and those who leave the larger cities to retreat to the Great Lakes coast almost always experience a broadened awareness of the environmental problems. These issues, like eutrophication and toxic algae blooms, are removed from the daily experience of urban life. Fertilizer runoff from the manicured lawns in the suburbs, human biological waste, the impervious hardscapes of streets, agricultural erosion and pollution, as well as industrial waste are suppliers of hazardous toxins to the Great Lakes. These use groups have created contentious relationships between themselves and the natural environment in terms of urban health, in addition to environmental despair. Through the perpetual polluting of the Great Lakes, these groups are not only disconnecting from each other and the environment, but they are also further segregating themselves from those seeking recreation within the watershed. These entities are creating natural warfare against each other for the use of natural resources, with the Great Lakes being the greatest casualty. Imagine a young family visiting one of the many public and free Great Lakes to go swimming and spend time in nature, who instead comes upon a toxic algae bloom so thick, it covers as much of the lake as they can

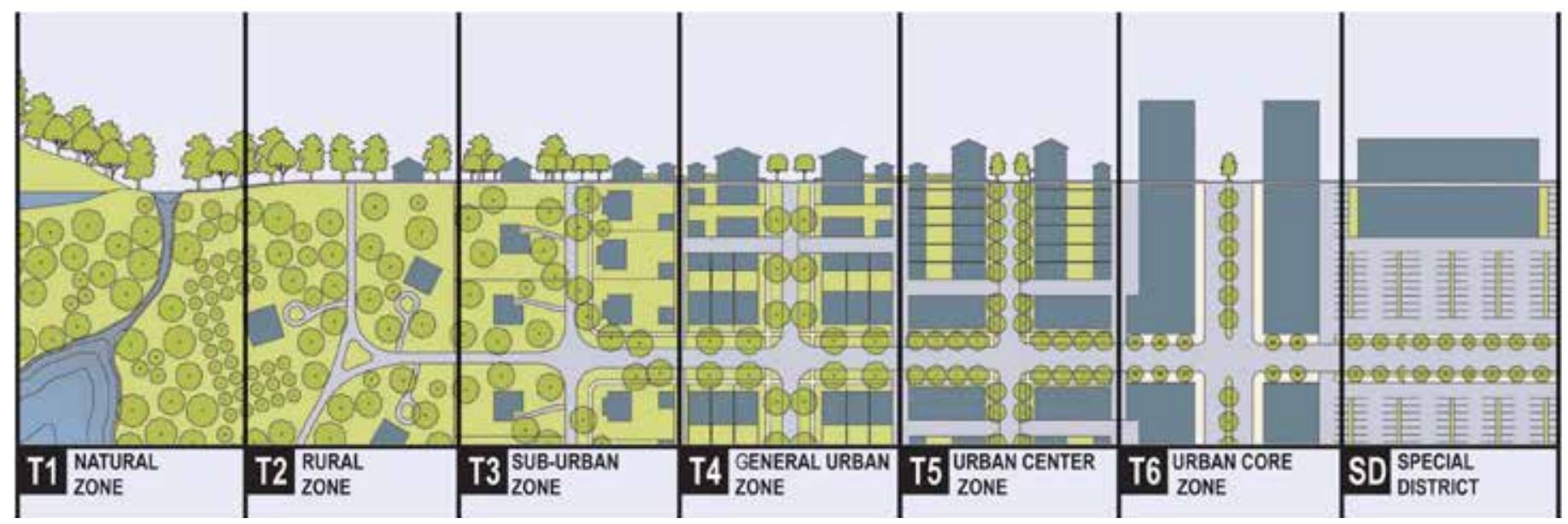

Figure 1. The "New Urbanist Transect," by Duany Plater-Zyberk \& Company, Center for Applied Transect Studies. 


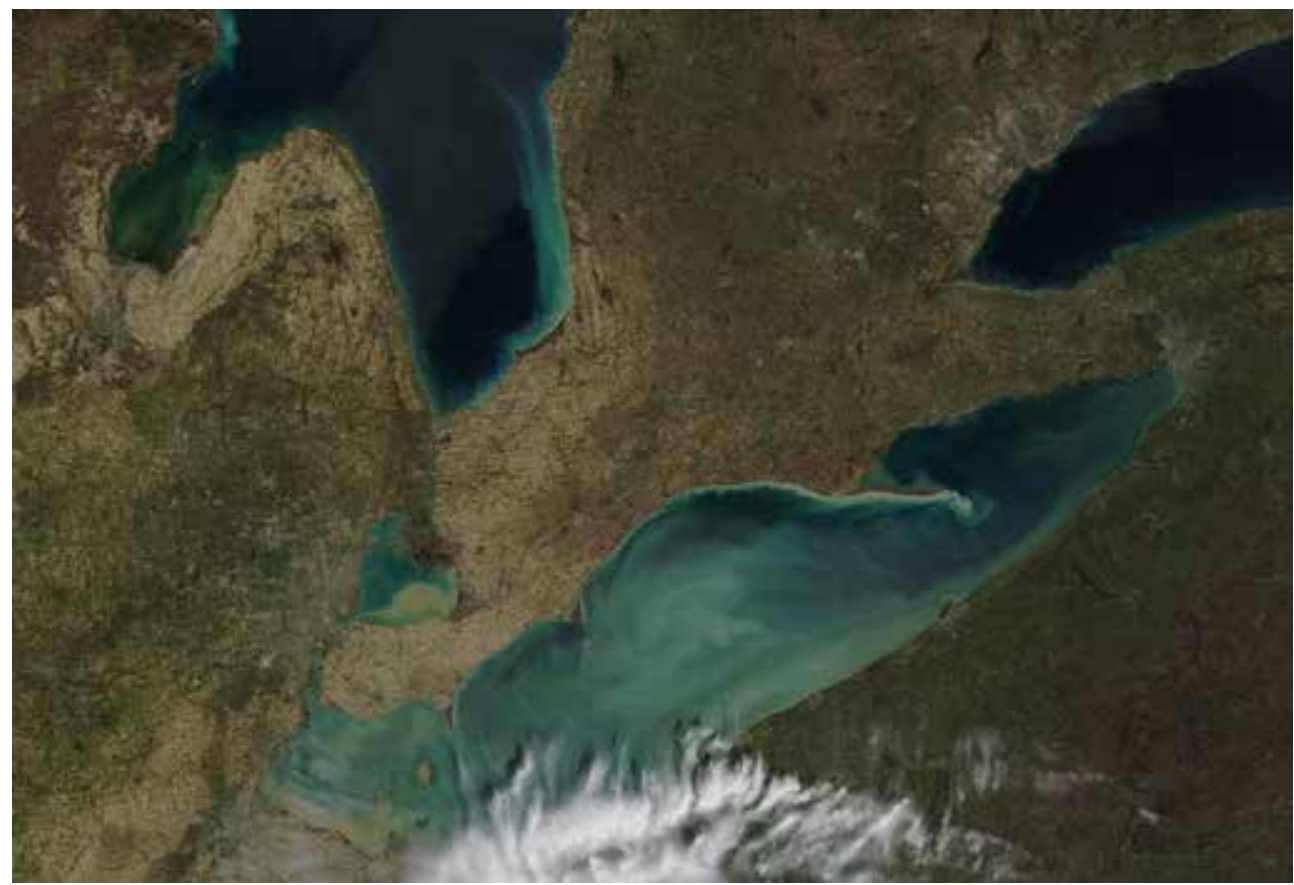

Figure 2. Lake Erie Algae Bloom.

see and is completely stagnant. This family is another casualty, unable to enjoy the same right to fresh water as many before them. The trickle-down effect of toxic runoff is not only an environmental injustice, but there also exists a social trickle-down effect that puts unintended populations at significant disadvantage as well. While factory farms and other large organizations in the West Lake Erie Basin continue to pollute the water, social and environmental injustice has become a way of life for vast populations of residents in the region.

There are substantial effects from toxic algae blooms in the Great Lakes, from environmental pollution, to urban health, to social detriment. If current policy continues, the efforts made to mitigate runoff from entering Lake Erie will shift these same issues from the toxic algae infestation to another environmental casualty, another social disadvantage, and further burdens on public health. It is critical to ask why the disconnection between suburbia, urbanism, agriculture, and industry with the natural world has not been considered as a topic of resolve, and if there are ways to not just mitigate the problem, but rather meet these issues head on. Is it possible to face up to the urban lifestyles, practices, routines, and methods of human habitation and push for something that breaks the "Whac-A-Mole" cycle?

\section{FRESHWATER URBANISM AND HEALTHY EARTH HABITATION}

Just as all civilizations have evolved, parasitic living can also evolve. Since the Great Lakes, specifically Lake Erie, have undergone so much pollution from a sundry of urban-environmental disconnects, pollution abetment 
or toxic mitigation are no longer viable solutions. Human existence finds itself at the forefront of the Anthropocene, and the toxic algae blooms in the Great Lakes fresh water basin are strong environmental indicators of the negative impact humans have had on the earth. Human habitation has influenced atmospheric, biospheric, geologic, hydrologic and an assortment of other natural ecologies and/or systems.

Rainfall does not only help to shape the landscape, but it is necessary for land-based life and delivers nutrients to the ocean. However, after the influences of agriculture, urbanism, and industry, it now collects toxins that result in the surplus of phosphorous and other nutrients in the Great Lakes, causing complex detrimental biological and ecological impacts.

Humans and human habitation must evolve to meet the demands of the environmental needs of the Anthropocene for resilient survival. There are ways that life can sustain, and flourish, that do not further harm the environment, but in fact, thrive from the earth's urban-induced virus and subsequent fever. Freshwater Urbanism tackles the negative environmental effects in the Great Lakes region caused by destructive contemporary urbanism, using these adverse consequences to generate healthier earth habitation. What exactly is "healthy earth habitation?" (Have we even seen it?)

Healthy earth habitation is a mutually beneficial relationship. Many argue that rerouting toxic wastewater from the fresh water to ground water is a sign of environmental activism, particularly government and policy officials, who benefit from the root causes of the pollution.

Solutions like these still position an opposing relationship between humans and the environment. Without altering urban lifestyles and principles, such as discontinuing urban-based behaviors that are causing environmental illness, there will be a continued discord between the environment and insatiable human appetite. It is necessary to prioritize the natural environment over the proclivities of human habitation.

Healthy earth habitation occurs when humans directly support ecological and environmental functions of the natural world without sacrificing health and wellbeing. This creates a mutually beneficial existence. Freshwater Urbanism is a method of achieving a mutually beneficial relationship between the natural environment and urbanism, supporting healthy earth habitation. In the case of Lake Erie and the Great Lakes, it is vital to preserve the natural resource of fresh water as this is critical for life. Therefore, any type of human existence along fresh water coasts has the special responsibility to regard itself as Freshwater Urbanism, intentional societies dedicated to preserving this critical natural resource. The overall water body of the Great Lakes itself is an important spatial environment that is infected, its illness being indicative of the separation between urbanism and the natural environment. To preserve this resource, lessening the divide between urbanism and nature is needed, bringing people into close proximity with nature and requiring intimate ecological relationships not yet realized. 


\section{WATER-BORNE MICRO-CITIES:}

\section{A PROPOSAL FOR A NEW ECOLOGICAL TYPOLOGY}

To support the notion of Freshwater Urbanism as a new, Anthropocenebased urban model and theory, it is necessary to establish parameters to compose an urban morphology. An initial population of 20,000 people was established over an area of $4.5 \mathrm{sq}$. mi. [11,66 $\left.\mathrm{km}^{2}\right]$ to create a generous urban density of 4,444 people per sq. mi. [1.715 people per $\mathrm{km}^{2}$ ]. In 2015, the largest infestation of toxic algae bloom was recorded in Lake Erie, producing scum that spanned approximately 300 sq. mi. [777 km²]. For comparison, the land area of New York City is 304 sq. mi. [789 km²], with Manhattan consisting of approximately $23 \mathrm{sq}$. mi. [59 km²] with an urban density of 72,000 people per sq. mi. [27.799 people per $\left.\mathrm{km}^{2}\right]^{2}{ }^{2}$ A typical midwestern city comfortably supports an urban density between $4,000-5,000$ people per sq. mi. [1.544-1.931 people per $\mathrm{km}^{2}$ ] thus, this influenced the selection of urban parameters to stay reflective of regional culture. For a successful illustration of this morphology, urban character remains, suggestions are made towards styles of human habitation and urban behaviors. To sustain a closed-loop ecological network, the following constraints were necessitated per standard usage in Michigan.

Table 1. Water-borne micro-city basis of design parameters.

\begin{tabular}{|c|c|c|}
\hline Utility & $\begin{array}{l}\text { Micro City } \\
\text { Daily Needs }\end{array}$ & $\begin{array}{l}\text { Single Person } \\
\text { Daily Needs }\end{array}$ \\
\hline Water & $\begin{array}{l}1.8 \text { million gallons } \\
(6,814 \text { liters })\end{array}$ & $\begin{array}{l}90 \text { gallons }^{3} \\
\text { (341 liters) }\end{array}$ \\
\hline Electricity & $\begin{array}{l}7.87 \text { million kBtu } \\
\text { (8.3 billion } \mathrm{kJ})\end{array}$ & $\begin{array}{l}\text { 143,600 kBtu }{ }^{4} \\
(151.5 \text { million } \mathrm{kJ})\end{array}$ \\
\hline Waste & $\begin{array}{l}\text { 7,227 gallons } \\
\text { (27,357 liters) }\end{array}$ & $\begin{array}{l}19.8 \text { gallons } \\
\text { (75 liters) }\end{array}$ \\
\hline
\end{tabular}

These parameters were utilized to provide baseline design conditions to be met for the optimum health, hygiene, and wellness of the following proposed water-borne micro-city design basis as a new urban paradigm for Freshwater Urbanism.

\section{Strategy 1: Infrastructural Coupling}

The first strategy involves the coupling of algae energy, solar energy, wind energy, and elements of nomadic living. Combining multiple sustainable and renewable infrastructures allows the micro-city to operate as a rechargeable battery, able to deliver energy as well as possess the mobility to follow sources of energy. 


\section{Algae Energy Generation}

The water-borne micro-city is mobile and can provide nomadic, renewable energy generation throughout the Great Lakes. As the farming of non-toxic algae becomes more prevalent, especially throughout the Midwest, it is critical to investigate the possibility of harvesting toxic algae as a fuel for energy needs of human habitation. Based on report findings that state one pound $[0,45 \mathrm{~kg}]$ of algae can be converted into 9,400 BTU, ${ }^{3}$ the micro-city of 20,000 people will require $851 \mathrm{lb}$. [386 kg] of algae to power the basic energy needs each day. Lake Erie is estimated to have 400 metric tons [882K lb.] of bioavailable phosphorous in the form of toxic algae, which could power a micro-city for 1,946 days, or nearly five years. In 2003 through 2017 alone, the severity of toxic blooms has increased by approximately $1,000 \%$ and studies project sustained levels of toxic algae through 2030 and beyond. This energy resource is becoming more abundant, yet more environmentally damaging by the year. The ability for humankind to flourish from the negative environmental consequences from years of contamination is a characteristic of Anthropocene-based evolution, and in doing so, the flourishing of humans is symbiotic with the natural world for succinct healthy earth habitation. Harvesting toxic algae can improve environmental conditions, while providing more energy than necessary for sustainable living. Thus, excess energy generation can be stored or classified as an agricultural resource, with a higher yield to payback than most agricultural crops that come from established factory farms in the Great Lakes region.

\section{Solar Energy Generation}

Conservatively, the Great Lakes receive an average estimate of $1,300.15 \mathrm{BTU} / \mathrm{sq}$. $\mathrm{ft} . /$ day [14.446 BTU/m²/day] of solar radiation. ${ }^{4}$ This lends to the coupling of solar power with algae biomass as a means to maximize and optimize energy production of the micro-city. Because of the micro-city's water borne morphology, there are virtually no light-blocking obstacles to obstruct solar radiation from the micro-city mass. Therefore, it is possible to collect enough energy to meet all electricity needs of the micro-city through $6,153 \mathrm{sq}$. ft. [572 $\mathrm{m}^{2}$ ] of photovoltaic panels, a meager less than $1 \%$ of the entire surface area of the micro-city. When nature is segregated from urbanism in planning, policy, and theory, there is the potential to overlook important points of research that could otherwise synthesize infrastructural and operational processes. The Great Lakes watershed is largely left out of research that quantifies solar radiation throughout the United States, measuring only the surface area of land instead. Despite the lack of human habitation within the lakes themselves, water is a surface that does, in fact, receive solar radiation. For the purposes of this research, we interpolated solar gains based on the low average for the upper Midwest region to speculate the possibility of offshore solar panels for energy generation. 


\section{Wind Energy Generation}

There is much discussion and progress regarding onshore wind energy generation. However, measured winds are strongest offshore. The micro-city can harness these strong offshore winds through turbines that, because of the absence of physical obstructions, can have longer wing spans to generate more energy. The turbine infrastructure can also double as light towers, alarms, or additional urban framework. The integration of wind turbines into the everyday life for inhabitants on the micro-city places people in direct connection with the source of energy, and the unique typology of the micro-city allows for strategic adaptation of new infrastructural approaches that prioritize environmental concerns to preserve healthy earth habitation. In conventional planning, large wind turbines are mostly located in isolated, rural areas segregated from human habitation. The generation of wind energy and the physical turbines can also provide power and strength to act as a propellant, like a sail on a boat. One offshore-designed turbine with wingspans of $150 \mathrm{~m}$ [492 ft.] can generate enough power to sustain 5,000 free-standing homes, ${ }^{5}$ while taking up an insignificant amount of area in the micro-city.

\section{Nomadic Renewable Energy Generation}

Prior to the onset of contemporary agriculture, human survival largely depended on nomadic traditions. Current land rights issues and regulatory ordinances limit nomadic culture within Western society; however, many theorists argue that nomadic ways of living provide people with new landscapes and new perspectives, which can strengthen the human mind, therefore lending to a nostalgic, yet evolved, state of civilization. Through its mobility, this micro-city can follow the presence of toxic algae blooms, solar

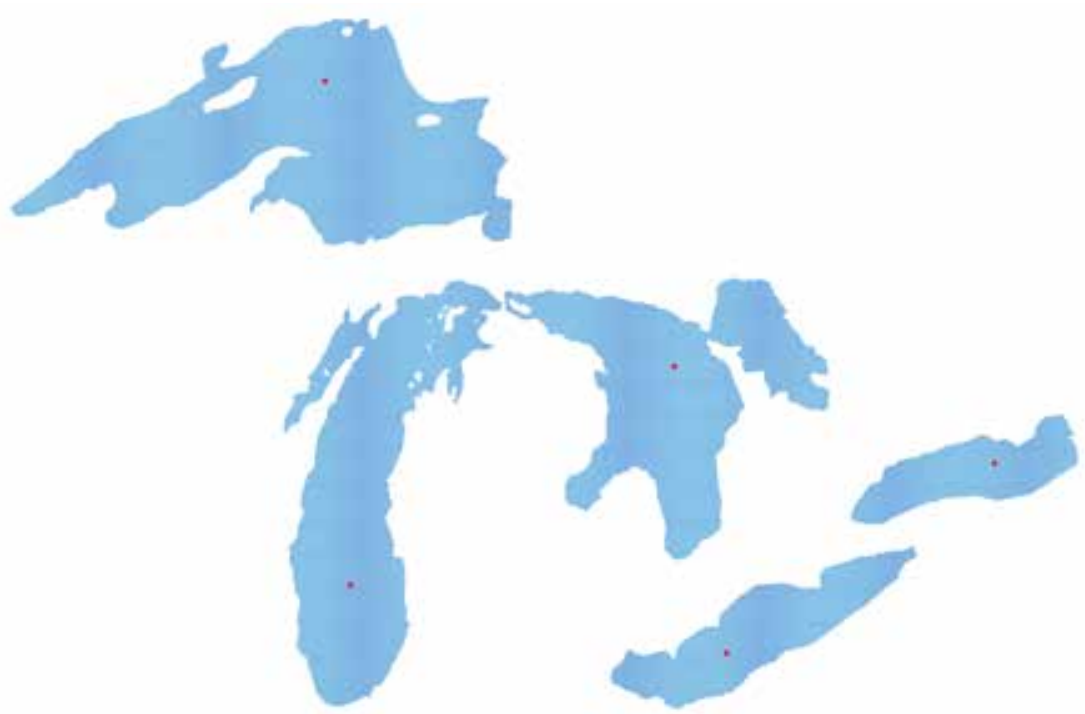

Figure 3. Water-borne micro-city distribution throughout the Great Lakes. 
radiation, and wind to collect the maximum amount of energy for generation and/or storage. With the ability to connect and "plug-in," the micro-city can transport energy from city to city along the Great Lakes, acting as a backup generator or an energy supplier, directly supporting coastal cities and overarching Freshwater Urbanism. Under the current urban energy structure, energy resources must be harvested and brought to facilities for creation, conversion, and distribution. Even in state-of-the-art energy facilities that are converting algae to energy, infrastructures must be built to create synthetic, on-ground algae "farms." The micro-city, on the other hand, is an entire municipality that travels to the natural resource, for a streamlined process causing less environmental taxation. Directly pairing energy generation, conversion, and storage within and around 20,000 residents forces the entire course of action to maintain transparency, stewardship, and a knowledge base of the fragility of energy in sustaining human life.

\section{Strategy 2: Direct Interaction with Water}

The second strategy supporting water-borne micro-cities as a new ecological typology for healthy earth habitation involves one's relationship with water. The direct experience with the Great Lakes reinforces emotional connectedness, increasing awareness of the watershed that is the lifegiving powerhouse for the micro-city. The state of the water indisputably affects resident life by directly showcasing the ominous condition of the Great Lakes during the onset of the Anthropocene.

In contrast, a person living in suburban Ohio who maintains a beautiful front lawn by fertilizing and watering it regularly may never realize the extent of the environmental harm caused by introducing phosphorous-rich fertilizer into the water system. While the lawn flourishes, the fertilizer tricklesdown and is discharged into the Great Lakes, where the homeowner will likely never encounter the thick, toxic algae scum created from the fertilizer runoff. When beautiful, manicured lawns are the standard of one's interaction with nature, and the local city ordinances reinforce yard requirements, building setbacks, and suburban zoning strategies, there is a severe discord with the natural environment. The negative implications of these socially, politically, and economically accepted lifestyles, thus, contribute greatly to the impaired state of the Great Lakes and foster estranged relationships between human habitation and the watershed. Imagine if this front yard was fresh water in the Great Lakes, and these lifestyle practices promoted the health of the water. For the micro-city, fresh water is the front yard.

As the typology for this new class of Freshwater Urbanism is idealized through these strategies, morphological forms begin to naturally adapt organic systems and processes. The elements of biomimicry are subtle and may seem more technologically innovative than organic. Despite 
that, the mechanical implications in the architecture of this micro-city are meant to benefit the survival of human life and natural life, and is therefore reminiscent of natural evolution. Technicalities aside, the predominant aspect to the micro-city is its relationship with water; a remedy to alienated, contemporary urbanism. By placing human life on top of sensitive natural resources for survival, people are forced to witness natural systems daily, live lower-impact, more thoughtful lives, while also feeling a sense of ownership over the Great Lakes, because after all, the fresh water does become the front yard for the micro-city.

\section{Strategy 3: Vertical Inversion of Zoned Use}

Providing an environment that is viable to human life, capable of generating natural energy, and is beneficial to the biological ecosystem are not the only dynamic infrastructural opportunities for a water-borne micro-city. On shore, land use is often regulated by policy, zoning ordinances, codes, and necessary civil groundwork. Off shore, however, the ability to invert the traditional transect is not only possible, but it is practical. Many of the necessary functions deal directly with water, from the cleansing of the water, to harvesting toxic algae and converting it to usable energy, to the filtration systems, to agricultural opportunities, and recreation. While a typical onshore transect limits the boundaries and interactions of the natural environment with urban areas, a vertically inverted offshore zoning system reverses the way urban life situates itself in relation to air, water, and land. This strategy merges a theoretical environmental typology with pragmatic engineering, offering a realistic solution to commonly idealized urban notions. It is in this reimagined zoned use that Freshwater Urbanism takes absolute responsibility for the greatest health and wellness of not only residents, but also plants and animals. This model emphasizes a realistic approach towards healthy earth habitation.

The proposal for explorative use of volumetric zoned area is based on synthesized blending of environmental and urban needs. By merging these two environments, each one becomes dependent and interlaced within the other. The micro-city cannot flourish if the natural environment does not also flourish. When making improvements and/or daily maintenance to the urban infrastructure, as many traditional cities do, the efforts will therefore advance the health of water and air qualities. This relationship embodies a mutually beneficial symbiotic connection that has the potential to reach further than within its own direct proximity. Because the Great Lakes watershed connects to the Atlantic Ocean and Arctic Circle throughout various North American tributaries, the innovative, inverted zoning of the micro-city has the ability to enact positive changes throughout the entire continent.

The merging of natural and urban survival needs brings forth an intimate awareness of consequences from urban disconnect on natural ecosystems, as well as public understanding of lifestyle habits that have low to no impact 


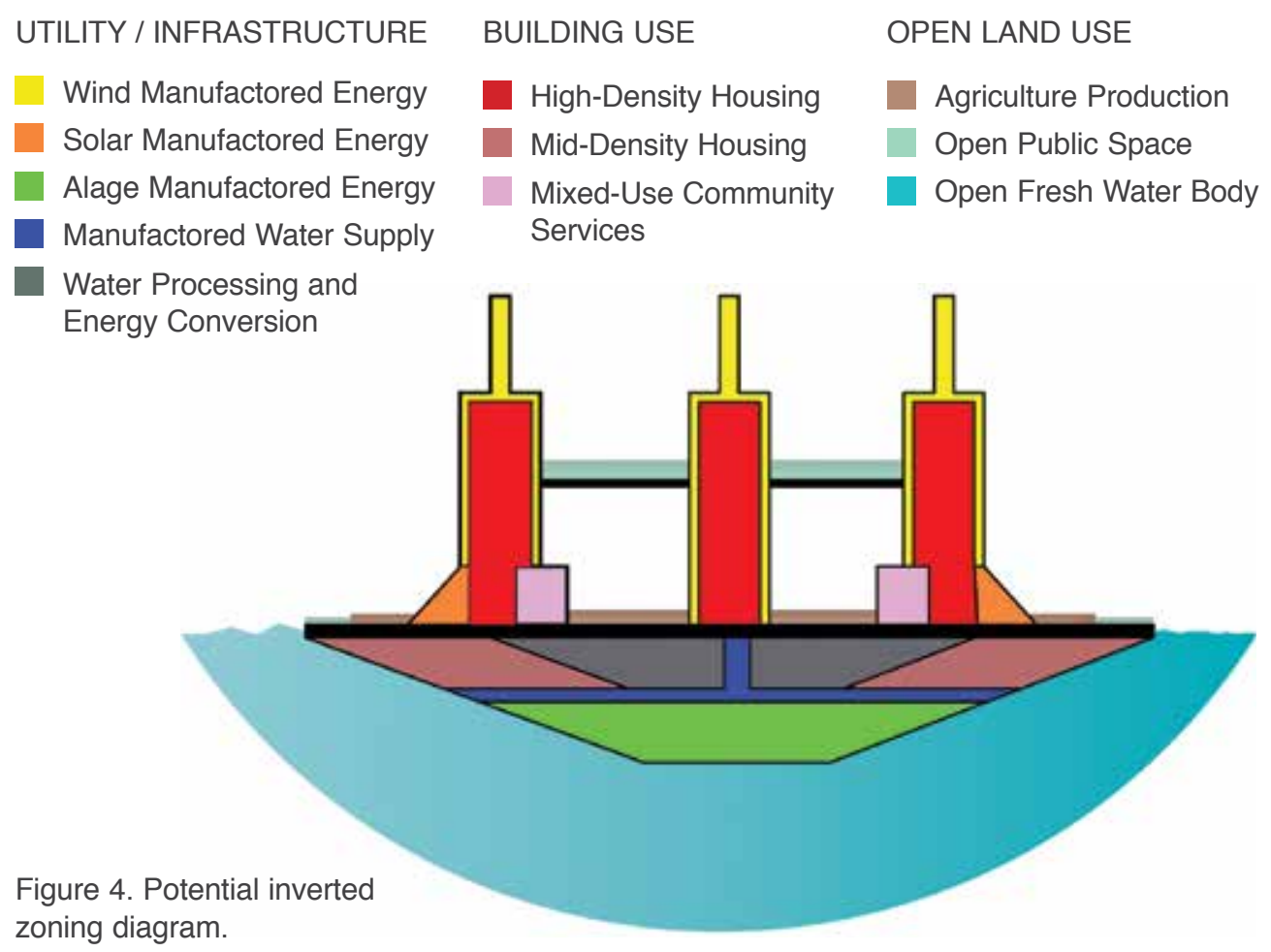

on the natural environment. The health and wellness of residents on the micro-city and coastal cities like Toledo are determined by the success of the natural environment. The social awareness and directionality of the inverted transect calls into question importation policies, which will become more prevalent as political discussions take place regarding the running of oil pipelines through the Great Lakes. While most people in the region do not reside directly next to a Great Lake, it is easy to allow political actions like oil pipelines, or the growth of toxic algae, for that matter, to occur. For the residents on the micro island whose surrounding "yards" are fresh Great Lake water, the condition of the lake water is vital to a healthy existence and enjoyable natural resources, which will spark local and residential activism based on the NIMBY (Not In My Backyard) pejorative. By allowing space above, on, and below the water surface, residents are provided unique opportunities to access vast views and underwater ecosystems; this will become a part of the everyday experience on the micro island. The vertical inversion of zoned use is not simply a pragmatic infrastructural solution, but it is also a way to enhance human life in new ways.

\section{Strategy 4: Localized Placement to Resources}

Water

The vertical and inverted zoning structure as described creates a different organization of programs and resources that are not necessarily combined through conventional urban planning. In doing this, residential units are 
placed on top of industrial and civil infrastructures, in addition to being situated significantly closer to natural resources. What would it be like to live on top of the water that we drink, or the energy that we use? Rather than collecting fresh water and processing it through filtration channels to ultimately provide clean water to household faucets through traditional urban water systems, the design of the water-borne micro-city eliminates the need for unnecessary urban infrastructure by providing a direct filtering channel from the lake water to the micro-city residents, not unlike natural vegetative root systems. The fresh water basin becomes a large storage tank, syphoned when necessary with on-the-spot filtration. Due to the micro-city harvesting toxic algae and cleansing the water, the filtration needs are comparatively less than other standard water treatments, adding another beneficial aspect to living in close quarters to the natural resources needed to sustain life. With the entire micro-city functioning as an island, agricultural practices are directly impacted, as this will provide the possibility of bottom up irrigation, or hydroponic agriculture.

\section{Energy}

With the elimination of substantial infrastructure, less energy is utilized to process resources. The micro-city generates energy from algae, solar radiation, and wind. The energy can then be directly converted and distributed on-site, because the micro-city has localized placement to these resources. These infrastructures - wind turbines, photovoltaic panels, and algae harvesting - are coupled with other urban needs, such as light towers and shelters - providing more direct energy fulfillment to specific needs. The localized, coupled course of generating energy is a $1: 1$ production, as no energy is lost in the direct transferring and conversion process. Residents will be integrated within the ecology of energy generation, which will provide energy education, specialized life experiences, and a broadened awareness of the dire need for a mutually beneficial, symbiotic relationship between natural and artificial environments. The energy generation processes on the micro-city are non-harming to residents, allowing humans to exist nearby and occupy shared space with these industrial programs. Disparately, conventional energy generation causes such significant air pollution, $\mathrm{CO}_{2}$ emissions, as well as soil and water contamination, that industry must be zoned at a far distance from residences.

\section{Food}

Through localized water and energy sources, agricultural practices are benefitted greatly. The re-allotment of zoning relationships allows the micro-city to introduce agricultural processes into daily life, rather than pushing farms to the city edges. In a similar approach to the streamlining of energy and water infrastructures, the integration of residential with natural and agricultural environments means that the transportation, processes, and packaging of food is no longer necessary. With direct, natural access 
to irrigation, increased moisture in the air, and greater access to sunlight, agriculture has the potential to flourish better in the micro-city than through conventional farming inland. Through hydroponics and traditional methods of growing, the micro-city will maximize these resources, while also presenting precedence for amended regional agricultural practices. Algae may also be used as a natural fertilizer in addition to compost; a closed-loop, localized method of living. The lifestyle changes for residents through dietary changes and lessened energy needs will result in evolved, Anthropocene-based knowledge and skills.

\section{Strategy 5: Ecological Based Infrastructure "Plug-In"}

As the water-borne micro-city is fully surrounded by and dependent on fresh lake water, it is essential to redesign the process of wastewater and waste disposal from the existing conventional methods in urbanism, which have led to the toxic algae bloom infestation. Existing waste removal strategies involve polluting natural systems, creating a parasitic relationship between human habitation and natural ecosystems. Being a symbiotic form of Health Earth Habitation that supports the responsibility of caring for the Great Lakes and embracing Freshwater Urbanism, the micro-city can positively contribute to natural environments. By plugging into an urban morphology that is closer to natural systems through biomimicry and careful consideration of resources, it is possible to filter biological waste and convert it into a biogas through fermentation or anaerobic digestion. With the use of steam turbines, the biogas can provide heating and other energies to the micro-city.

\section{DISCUSSION}

This speculative article serves as a call to action: there are alternate forms of living that more directly relate to healthy fresh water ecology that need to be explored. The presence of toxic algae blooms in the Great Lakes is not a natural phenomenon, but rather a result from urbanism in ecological discord. While the infection of toxic algae in the fresh water is visible, many of the other symptoms of environmental inharmoniousness are not yet fully understood or felt. By finding opportunities for improved symbiotic relationships within nature to eliminate debilitating parasitical environmental exploitations, co-existence between human habitation and the natural world can not only continue, but come together to create new morphological systems. The urban morphologies discussed in this report present strategies towards an adaptable typology for urban resiliency through healthy earth habitation and Freshwater Urbanism.

It is critical to consider the Great Lakes watershed as a spatial environment, not just a natural resource. The Great Lakes are more than just a space, but they are a place. The fresh watershed is a place for habitation, for energy generation, for health and wellness, and for survival. Research 
and conjectural investigations should continue, as should explorations into the harvesting of toxic algae blooms for renewable energy. Toxic algae blooms are a growing problem not only in the Great Lakes region, but also in fresh water basins globally. Conventional, Western-based urban lifestyles and policies encourage people and planning programs to maintain a distance from natural and rural land, following the traditional rural to dense urban transect. As the age of Anthropocene settles in, humans need to accept new ideas for synthesized existence and begin to lessen the divide between human and nature. The tolls on the environment are growing daily, and stakeholders need to consider adaptive responses to pending environmental states or continue playing "Whac-A-Mole" at the expense of human and environmental health alike. The first changes must begin on a social behavioral level; discontinuing the accommodation of disproportionate human appetites and lifestyles.

Through coupling of energy resources, plugging into biomimicry planning ideals, thriving from negative environmental consequences of urbanism, and improving the state of the natural environment through mutually beneficial relationships, the water-borne micro-city represents a prototype urbanism; an urban morphology that can help preserve the Great Lakes. Instead of just mitigating negative changes to the environment through rerouting agricultural runoff, it is necessary to embrace inevitable detrimental conditions to accomplish the evolutionary state required for human survival and environmental health.

\section{Notes}

1. Associated Press, "2015 Lake Erie Algae Bloom Largest on Record," Detroit Free Press, November 11, 2015, http://www.freep.com/story/news/local/michigan/2015/11/11/ 2015-lake-erie-algae-bloom-largest-record/75569602/.

2. New York City, Department of City Planning, "New York City Population," NYC Population Facts, https://www1.nyc.gov/site/planning/data-maps/nyc-population/population-facts.page.

3. See "Energy and Algae" for value predication.

4. Photovoltaic resource map created by the National Renewable Resource Lab was used to determine assumed average PhotoVoltaic coverage and potential energy generation on Great Lakes water bodies (see Roberts 2012).

5. Estimate based on the use of GE's Haliade 150-6MW off shore wind turbine (see General Electric Company 2015).

\section{References}

Alarcón, María Arquero De, Jennifer Maigret, Susan Landfried, and Bin Zhang. "Visualizing the Dynamic Shorelands of the Great Lakes." Michigan Journal of Sustainability 4 (Summer 2016). doi: http://dx.doi.org/10.3998/mjs.12333712.0004.005.

Asmare, Abraham M., Beranu A. Demessie, and Ganti S. Murthy. "Theoretical Estimation the Potential of Algal Biomass for Biofuel Production and Carbon Sequestration in Ethiopia." International Journal of Renewable Energy Research 3, no. 3 (2013).

Associated Press. "2015 Lake Erie Algae Bloom Largest on Record." Detroit Free Press, November 11, 2015. Accessed September 09, 2017. http://www.freep.com/story/news/ local/michigan/2015/11/11/2015-lake-erie-algae-bloom-largest-record/75569602/. 
Barry, Amanda, Alexis Wolfe, Christine English, Colleen Ruddick, and Devinn Lambert. 2016 National Algal Biofuels Technology Review. Washington DC: U.S. Department of Energy, June 2016. https://energy.gov/sites/prod/files/2016/06/f33/national_algal_ biofuels_technology_review.pdf.

Brooks, Bryan W., James M. Lazorchak, Meredith D.A. Howard, Mari Vaughn V. Johnson, Steve L. Morton, Dawn A.K. Perkins, Euan D. Reavie, Geoffrey I. Scott, Stephanie A. Smith, and Jeffery A. Stevens. "In Some Places, in Some Cases, and at Some Times, Harmful Algal Blooms Are the Greatest Threat to Inland Water Quality." Environmental Toxicology and Chemistry 36, no. 5 (2017): 1125-127. doi: https://doi.org/10.1002/etc.3801.

Bureau of Ocean Energy Management. "Offshore Wind Energy." Accessed September 09, 2017. https://www.boem.gov/Offshore-Wind-Energy/.

Chen, Hongzhang, and Lan Wang. "Coproducts Generated from Biomass Conversion Processes." Technologies for Biochemical Conversion of Biomass, 2017, 219-64. doi: https://doi.org/10.1016/b978-0-12-802417-1.00009-0.

Conroy, Joseph D., Douglas D. Kane, Ruth D. Briland, and David A. Culver. "Systemic, Early-Season Microcystis Blooms in Western Lake Erie and Two of Its Major Agricultural Tributaries (Maumee and Sandusky Rivers)." Journal of Great Lakes Research 40, no. 3 (2014): 518-23. doi: https://doi.org/10.1016/j.jglr.2014.04.015.

Environmentally Concerned Citizens of South Central Michigan (ECCSCM). "Contamination. Monitoring, Reporting, Educating about CAFO Pollution." Accessed September 09, 2017. http://nocafos.org/contamination.

- - Follow the Manure: Factory Farms and the Lake Erie Algae Crisis. Lansing MI, USA: Sierra Club. November 17, 2015.

Darzins, Al. "Algal Biofuel Technologies." PowerPoint presentation presented at States Biomass/Clean Cities Web Conference, November 6, 2008.

Davis, R., C. Kinchin, J. Markham, E.C.D. Tan, and L.M.L. Laurens. Process Design and Economics for the Conversion of Algal Biomass to Biofuels: Algal Biomass Fractionation to Lipid- and Carbohydrate-Derived Fuel Products. Golden CO, USA: National Renewable Energy Laboratory, September 2014.

Gao, Yihe, Chapin Gregor, Yuanjie Liang, Dawei Tang, and Caitlin Tweed. "Algae Biodiesel - a Feasibility Report." Chemistry Central Journal 6, no. 1 (2012). doi: https://doi.org/10.1186/1752-153x-6-s1-s1.

General Electric Company. GE's Haliade 150-6MW - High Yield Offshore Wind Turbine. PDF document. GE Renewable Energy of General Electric Company, 2015.

Gilbert, J. "Nomadic Territories: A Human Rights Approach to Nomadic Peoples Land Rights." Human Rights Law Review 7, no. 4 (October 2007): 681-716. doi: https://doi.org/10.1093/hrlr/ngm030.

Ho, Jeff C., and Anna M. Michalak. "Phytoplankton Blooms in Lake Erie Impacted by Both Long-Term and Springtime Phosphorus Loading." Journal of Great Lakes Research 43, no. 3 (June 2017): 221-28. doi: https://doi.org/10.1016/j.jglr.2017.04.001.

Holden, Sarah. "Are Harmful Algae Blooms (HABs) a Problem in Michigan's Inland Lakes?" PowerPoint presentation. Water Resources Division, Michigan Department of Environmental Quality. April 2016.

Laurens, Lieve M.L., Keith E. Cooksey, Jim Sears, Mark Edwards, Craig Behnke, Niko Schultz, Steve Howell, Gina Clapper, Robert Gardener, Emillie Slaby, et al. "Industrial Algae Measurements." PDF document. Technical Standards Committee of Algae Biomass Organization, September 2015.

National Oceanic and Atmospheric Administration (NOAA). "Lake Erie Harmful Algal Bloom Forecast." Lake Erie Algae. Accessed September 9, 2017. http://lakeeriealgae.com/forecast/.

- -. "NOAA, Partners Predict Severe Harmful Algal Bloom for Lake Erie." Accessed September 9, 2017. http://www.noaanews.noaa.gov/stories2015/20150709noaa-partners-predict-severe-harmful-algal-bloom-for-lake-erie.html.

New York City, Department of City Planning. "New York City Population." NYC Population Facts. Accessed September 9, 2017. https://www1.nyc.gov/site/ planning/data-maps/nyc-population/population-facts.page.

Obenour, Daniel, Isabella Bertani, Nathan Manning, Drew Groneworld, Craig Stow, and Donald Scavia. "2017 Western Lake Erie Harmful Algal Bloom (HAB) Forecast." PDF document. North Carolina State University, University of Michigan, NOAA Great Lakes Environmental Research Laboratory (GLERL), July 13, 2017. 
Orosz, Matthew S., and David Forney. A Comparison of Algae to Biofuel Conversion Pathways for Energy Storage Off-Grid. Cambridge MA, USA: Massachusetts Institute of Technology, College of Environmental Engineering, May 2008.

Pond Technologies Inc. "Energy and Algae." Accessed September 09, 2017. http://pondtechnologiesinc.com/technology/energy-and-algae/.

Rekoske, Jim. "The Algae to Fuels Value Chain." PowerPoint presentation. Honeywell International. June 13, 2011.

Renewable Energy UK. "Calculate KWh Generated By Wind Turbine" The Renewable Energy Website. Accessed September 9, 2017. http://www.reuk.co.uk/wordpress/wind/ calculate-kwh-generated-\%20by-wind-turbine/.

Roberts, Billy J. "Photovoltaic Solar Resource of the United States." Map. In National Renewable Energy Laboratory. Golden CO, USA: National Renewable Energy Laboratory (NREL), 2012.

Rose, C., A. Parker, B. Jefferson, and E. Cartmell. "The Characterization of Feces and Urine: A Review of the Literature to Inform Advanced Treatment Technology." Critical Reviews in Environmental Science and Technology 45, no. 17 (February 2015): 1827-879. doi: https://doi.org/10.1080/10643389.2014.1000761.

Samples, Amy, Catherine Riseng, and Jonathon Day. "Engaging Marina and Harbor Operators in Climate Adaptation." Michigan Journal of Sustainability 3 (Spring 2015). doi: https://doi.org/10.3998/mjs.12333712.0003.004.

Singh, Manjinder, Rekha Shukla, and Keshav Das. "Harvesting of Microalgal Biomass." In Biotechnological Applications of Microalgae: Biodiesel and Value-Added Products, 77-88. Boca Raton FL, USA: CRC Press, 2013. doi: https://doi.org/10.1201/b14920-7.

United States Geological Survey. "Water Questions \& Answers - How Much Water Does the Average Person Use at Home per Day?" The USGS Water Science School. Accessed September 9, 2017. https://water.usgs.gov/edu/qa-home-percapita.html.

Wood, Daniel, and Sarah Gerrity. "How Much Do You Consume?" U.S. Department of Energy. Accessed September 9, 2017. https://energy.gov/articles/how-much-do-you-consume.

\section{Credits}

Figure 1: Public domain, https://transect.org/rural_img.html.

Figure 2: Public domain, https://www.dvidshub.net/image/844415.

Figure 3: Image created by the author.

Figure 4: Image created by the author.

Dustin Altschul is an Adjunct Professor of Architecture at Lawrence Technological University emphasizing technological integration and sustainable innovation in correlation to natural and built ecological systems. Dustin holds a Master of Architecture and a Master of Urban Design from Lawrence Technological University. His research focuses on multivariable optimization for automated form finding of spatial environments and climate responsive architecture. Dustin is also Co-Founder and Principal of Hungry Architecture, a research-based architectural practice dedicated to generating integrated perspectives in design and new approaches to spatial habitation. E-mail: dustin@hungryarchitecture.com

Kim Buchholz is a researcher, designer, and graduate architecture student at the Kendall College of Art and Design of Ferris State University, where she received a B.S. in Art History and a B.F.A. in Interior Design. Her research focuses on explorative form and material pertaining to issues of animal and environmental welfare, healthy urbanism, social equity as well as environmental psychology. Kim is Co-Founder and Director of Design at Hungry Architecture and she recently received a Golden Apple Architectural Residency Fellowship in DownEast ME, USA. E-mail: kim@hungryarchitecture.com 